\title{
ИСТОЧНИКИ БИОЛОГИЧЕСКИХ СВОЙСТВ И ХОЗЯЙСТВЕННО ЦЕННЫХ ПРИЗНАКОВ ДЛЯ СЕЛЕКЦИИ ЯЧМЕНЯ
}

\section{A.V. Zaushintsena}

\section{THE SOURCES OF BIOLOGICAL PROPERTIES AND ECONOMICALLY VALUABLE TRAITS FOR BARLEY SELECTION}

Заушинцена А.B. - д-р биол. наук, проф. каф. экологии и природопользования Кемеровского государственного университета, г. Кемерово. E-mail: alexaz58@yandex.ru

Цель исследования: выявление перспективных сортов для практической селекции ячменя. В Кемеровской области изучено 110 сортов (2013-2016 г2.). Из них из Швещии было 0,9%; Франции - 0,9; Германии - 8,1; Чехии - 10,8; Латвии - 5,4; Эстонии - 0,9; США - 11,7; Беларуси - 4,5; Украины - 4,5; Казахстана - 2,7; России - 55 \%. Их сравнили с контрольными сортами Биом, Никита (Западная Сибирь). По продолжительности вегетационного периода выделено 3 группы ячменя: 1-я группа с коротким вегетационным периодом (до 73 суток) - 14 \%; 2-я групnа имеет среднюю продолжительность (74-78 суток) - 56 \%; 3-я группа с длинным периодом (более 78 суток) $14 \%$. Представителями первой группы являются: Биом (Новосибирская обл.), Scarlett (Германия), Iduтеја (Латвия), Нутанс 290 (Саратовская обл.), Рубикон (Краснодарский кр.), Тандем (Кировская обл.). В среднем за 4 года у стандартных сортов Биом и Никита формируется 243-282 продуктивных стеблей на $1 \mathrm{M}^{2}$. Достоверно высокое число продуктивных стеблей на 1 м² у сортов: Нутанс 553 (Украина), Адамовский 1 (Беларусь), Idumeja (Латвия), Madonna (Чехия). Их было на 10,2-28,3 \% больше, чем у контрольных вариантов Биом и Никита. Масса 1000 зерен не превышает 47,0 г. Существенных различий между ними в среднем за три года не наблюдалось. По урожаю зерна выделены сорта: Нутанс 553 (Украина), Адамовский 1 (Беларусь), Idumeja (Латвия), Madonna (Чехия).

Ключевые слова: ячмень, сорт, продуктивность, генетические источники, селекция.
Zaushintsena A.V. - Dr. Biol. Sci., Prof., Chair of Ecology and Environmental Management, Kemerovo State University, Kemerovo.

E-mail: alexaz58@yandex.ru

The purpose of the study was to identify promising varieties for practical selection of barley. In Kemerovo Region in 2013-2016 110 barley varieties had been studied. From them there were $0.9 \%$ from Sweden; France - $0.9 \%$; Germany - $8.1 \%$; the Czech Republic - $10.8 \%$; Latvia - $5.4 \%$; Estonia - $0.9 \%$; the USA - $11.7 \%$; Belarus - $4.5 \%$; Ukraine - $4.5 \%$; Kazakhstan - $2.7 \%$; Russia $55 \%$. They were compared with control varieties: Biom, Nikita (Western Siberia). According to the duration of vegetation season, 3 groups of barley were allocated: 1-st group with short vegetation period (up to 73 days) - $14 \%$; 2-nd group with average period (74-78 days) - $56 \%$; 3-rd group with a long period (more than 78 days) $-14 \%$. The representatives of the first group were Biom (Novosibirsk Region), Scarlett (Germany), Idumeja (Latvia), Nutans 290 (Saratov Region), Rubicon (Krasnodar Region), Tandem (Kirov Region). On average for 4 years in standard varieties Biom and Nikita 243282 productive stalks were formed on $1 \mathrm{~m}^{2}$. Authentically high number of productive stalks on $1 \mathrm{~m}^{2}$ was in the varieties Nutans 553 (Ukraine), Adamovsky 1 (Belarus), Idumeja (Latvia), Madonna (Czech Republic).They were 10.2-28.3\% higher than in control samples Biom and Nikita. The mass of 1000 grains did not exceed $47.0 \mathrm{~g}$. Essential distinctions between them on average for three years had not been observed. According to the grain harvest, the following varieties were selected: Nutans 553 (Ukraine), Adamovsky 1 (Belarus), Idumeja (Latvia), Madonna (Czech Republic).

Keywords: barley, variety, productivity, genetic sources, selection. 
Введение. Ячмень, как важная фуражная и пищевая культура, вновь востребован на мировом рынке. Его площади существенно сокращались еще в 2017 г. в Евросоюзе, Канаде, Австралии (на 15-17 \%). В России они варьируют в зависимости от спроса от 8,4 до 9,0 млн га [1, 2], а в 2019 г. составили 8,8 млн га [3]. Производство ячменя в 2018 г. составило 16980,9 тыс. тонн, что на 17,7 \% (на 3648,0 тыс. тонн) меньше, чем в 2017 году. Несмотря на это, за 5 лет сборы зерна выросли на 10,4 \%.

Важное значение придается адаптивности сортов к почвенно-климатическим условиям, стабилизации их зерновой продуктивности на уровне, обеспечивающем основные потребности кормопроизводства, пищевой промышленности. Поэтому в задачи селекционеров входит постоянное совершенствование сортов ячменя для конкретных локальных зон его возделывания с учетом изменения климатических ресурсов, усиления поражаемости растений вредоносными фритопатогенами и повреждения насекомыми, в том числе переносчиками вирусных заболеваний. Важно учитывать пищевую ценность продуктов переработки ячменя, включая содержание белков в зерне. Для расширения генетического разнообразия используют многие методы селекции, в том числе использование новых генетических источников ценных биологических свойств и хозяйственных признаков, экспериментальный мутагенез, полиплоидию и другие. Неисчерпаемым и значимым является всемерное использование мировых генетических ресурсов из генбанка Всероссийского института генетических ресурсов растений им. Н.И. Вавилова (ВИР), в котором сосредоточено 20000 образцов ячменя по 24 видам, которые поддерживаются в живом состоянии [4]. Нами такой подход к решению проблем селекции ячменя используется на протяжении более 30 лет.

Цель исследования. Выявление перспективных сортов из европейско-сибирского генетического центра для практической селекции ячменя.

Задачи исследования: провести оценку сортов по продолжительности вегетационного периода, числу продуктивных стеблей с единицы площади, числу зерен в колосе, массе 1000 семян, зерновой продуктивности растений; оп- ределить содержание белка в зерне; выделить генетические источники ценных свойств и продуктивности для практической селекции ячменя.

Объекты и методы исследований. В качестве объекта исследований в Кемеровской области изучено 110 сортов ячменя (2013-2016 гг.). Из Швеции в состав коллекции вошло 0,9 \% сортов от общего числа, Франции - 0,9\%, Германии 8,1, Чехии - 10,8, Латвии - 5,4, Эстонии - 0,9, США -11,7, Беларуси - 4,5, Украины - 4,5, Казахстана - 2,7, России - 55 \%. Их сравнили с контрольными сортами Биом, Никита (Западная Сибирь) по продолжительности вегетационного периода и элементам зерновой продуктивности растений.

Исследования проведены на опытном полигоне Кемеровского государственного университета в 62 км от г. Кемерово (база практики «Тюльберский городок»). Почвы - темно-серые лесные суглинистые по гранулометрическому составу. Содержание гумуса в пахотном горизонте $-8,7 \%, \mathrm{pH}_{\text {сол. }}-6,0$, содержание макроэлементов (NPK) среднее и высокое.

В годы исследований отмечены существенные различия по гидротермическому режиму: 2013 г. характеризовался недостатком тепла (на 1,5-3,0 ${ }^{\circ} \mathrm{C}$ ниже средней многолетней нормы) и чрезмерным увлажнением в течение всего летнего периода (выше нормы на 60-117\%), что отрицательно отразилось на росте и развитии растений, фрормировании продуктивности растений. В 2014 г. отмечен недостаток температур, холодным был май (на $2,9^{\circ} \mathrm{C}$ ниже средней многолетней нормы), близкими к норме остальные месяцы, При этом зафиксирован избыток влаги в мае, недостаток в июне (на $52,9 \%$ ) и июле $(12,5 \%)$ и близкие к норме показатели в августе. В 2015 г. отмечен ощутимый недостаток тепла (на $3,5^{\circ} \mathrm{C}$ ) в первой декаде июля, когда происходит формирование семени, и только в 2016 г. наблюдалась мягкая погода с близкими показателями к средней многолетней норме.

Исследования проведены в соответствии с методическими указаниями [5], ГОСТ 10840-64 [6], статистическая обработка проведена методом однофакторного дисперсионного анализа [7].

Результаты исследования и их обсуждение. Скороспелость у ячменя в Сибири - отличительное свойство от других зерновых культур и по сравнению с сортовым потенциалом в дру- 
гих регионах, где таких рискованных условий для выращивания культурных видов не существует. Во-первых, это важно для организации посевных и уборочных работ, когда за счет скороспелости ячменя более эффективно оптимизируются сроки посева и уборки. Как показывает практика, удается сохранить большое число площадей пшеницы для уборки без осыпания колоса, сильного полегания в условиях сырой ненастной погоды [8]. В нашем полевом опыте удалось все сорта ранжировать по группам спелости (рис.). Выделено 3 группы: скороспелые (14\%), среднеспелые (30\%) и среднепоздние (56 \%). Типичными представителями первой группы являются: Биом (Новосибирская обл.), Scarlett (Германия), Idumeja (Латвия), Нутанс 290 (Саратовская обл.), Рубикон (Краснодарский кр.), Тандем (Кировская обл.).

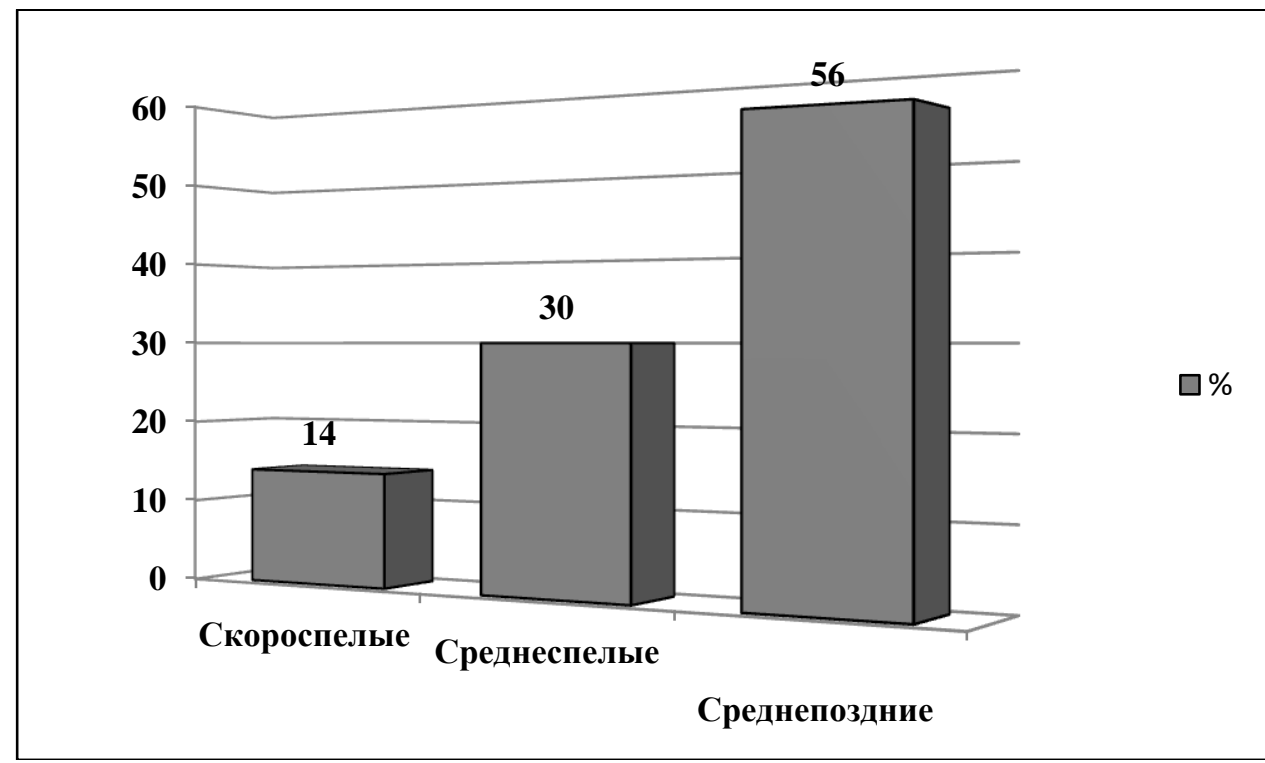

Распределение коллекции по группам спелости

Использовать для гибридизации местные формы из Восточной Сибири предложили Н.А. Сурин и др. [9]. Они тоже обращают внимание на скороспелость исходного материала, повышенную устойчивость к ранневесенним засухам, способность формировать высококачественное зерно в условиях дождливой и прохладной осени.

Важным показателем реакции сортов на условия выращивания является их зерновая продуктивность. Она зависит от числа продуктивных стеблей на единице площади, числа зерен в колосе, крупности семян.

В среднем за 4 года у стандартных сортов Биом и Никита формируются 243-282 продуктивных стеблей на $1 \mathrm{~m}^{2}$. Достоверно выше эти показатели были у образцов: Адамовский 1 (Беларусь), Idumeja (Латвия), Madonna (Чехия).

По числу зерен в колосе существенное преимущество также имели два первых из пере- численных. Масса 1000 зерен изучаемых сортов в среднем незначительно отклоняется от общего массива показателей в изучаемом сортименте и не превышает 47, 0 г.

За счет более высокого числа продуктивных стеблей на единице площади обеспечены достоверные положительные отличия (10,2-28,3 \%) по урожаю зерна у сортов: Нутанс 553 (Украина), Адамовский 1 (Беларусь), Idumeja (Латвия), Madonna (Чехия).

Сложнее всего вести селекцию ячменя на качество, в том числе как на повышение белка в зерне, так и на его понижение. Среди генофонда выделены сорта с устойчиво повышенным и параллельно с устойчиво пониженным содержанием белка в среднем за 4 года (табл. 2). Сохраняют низкую белковость зерна сорт Кемеровского НИИСХ Никита (12,7 \%) и Idumeja из Латвии $(12,7 \%)$. 
Элементы продуктивности у перспективных сортов ячменя, 2013-2016 гг.

\begin{tabular}{|c|c|c|c|c|c|c|}
\hline $\begin{array}{c}\text { Номер по } \\
\text { каталогу } \\
\text { ВИР }\end{array}$ & Сорт & Происхождение & $\begin{array}{c}\text { Число продук- } \\
\text { тивных стеб- } \\
\text { лей на } 1 \text { м², } \\
\text { шт. }\end{array}$ & $\begin{array}{c}\text { Число зе- } \\
\text { рен в коло- } \\
\text { се, шт. }\end{array}$ & $\begin{array}{c}\text { Macca } \\
1000 \\
\text { зерен, г }\end{array}$ & $\begin{array}{c}\text { Macca } \\
\text { зерна, } \\
\text { г/м² }\end{array}$ \\
\hline- & $\begin{array}{c}\text { Биом } \\
\text { (стандарт) }\end{array}$ & $\begin{array}{c}\text { Новосибирская } \\
\text { обл. }\end{array}$ & 282 & 23 & 44,8 & 442 \\
\hline- & $\begin{array}{c}\text { Никита } \\
\text { (стандарт) }\end{array}$ & $\begin{array}{c}\text { Кемеровская } \\
\text { обл. }\end{array}$ & 243 & 22 & 42,5 & 464 \\
\hline \multirow[t]{2}{*}{30594} & Зерноградский & Ростовская обл. & 260 & 20 & 42,0 & 498 \\
\hline & Нутанс 553 & & 311 & 20 & 46,7 & 515 \\
\hline 30894 & $\begin{array}{c}\text { Адамовский } 1 \\
\text { (Беларусь) }\end{array}$ & Беларусь & 345 & 25 & 46,5 & 537 \\
\hline 30922 & Idumeja & Латвия & 358 & 24 & 45,6 & 513 \\
\hline 30940 & Madonna & Чехия & 345 & 20 & 43,4 & 520 \\
\hline \multicolumn{3}{|r|}{$\mathrm{HCP}_{05}$} & 44,0 & 0,36 & 2,41 & 38,4 \\
\hline
\end{tabular}

Содержание белка в зерне, \%

Таблица 2

\begin{tabular}{|c|c|c|c|c|c|c|}
\hline $\begin{array}{c}\text { Номер по } \\
\text { каталогу ВИР }\end{array}$ & Сорт & 2013 г. & 2014 г. & 2015 г. & 2016 г. & Среднее \\
\hline- & $\begin{array}{c}\text { Биом } \\
\text { (стандарт) }\end{array}$ & 13,6 & 14,2 & 15,0 & 15,3 & 14,4 \\
\hline- & $\begin{array}{c}\text { Никита } \\
\text { (стандарт) }\end{array}$ & 12,0 & 12,5 & 13,2 & 13,5 & 12,7 \\
\hline \multirow[t]{2}{*}{30594} & Зерноградский & 13,8 & 14,8 & 14,8 & 15,8 & 14,8 \\
\hline & Нутанс 553 & 13,4 & 15,0 & 16,5 & 16,7 & 15,4 \\
\hline 30894 & $\begin{array}{c}\text { Адамовский } 1 \\
\text { (Беларусь) }\end{array}$ & 14,0 & 15,3 & 15,5 & 16,6 & 15,3 \\
\hline 30922 & Idumeja & 12,4 & 12,6 & 12,7 & 13,2 & 12,7 \\
\hline 30940 & Madonna & 13,8 & 14,7 & 16,2 & 15,8 & 15,4 \\
\hline
\end{tabular}

Максимальными показателями белковости зерновки (15,3-15,4 \%) обладают сорта: Нутанс 553 из Украины, Адамовский 1, Madonna из Чехии.

Заключение. Таким образом, в условиях неустойчивой погоды 2013-2016 гг. наиболее перспективными генетическими источниками на закрепление скороспелости в гибридном материале являются следующие сорта: Scarlett (Германия), Idumeја (Латвия), Нутанс 290 (Саратовская обл.), Рубикон (Краснодарский кр.), Тадем (Кировская обл.).
В селекции на повышение зерновой продуктивности рекомендуется использовать сорта: Нутанс 553 (Украина), Адамовский 1 (Беларусь), Idumeja (Латвия), Madonna (Чехия).

Для улучшения качества зерна по содержанию белка на кормовые цели интерес представляют: Нутанс 553 (Украина), Адамовский 1 (Беларусь), Madonna (Чехия). В направлении выведения пивоваренных сортов ячменя могут быть эффективными только 2 образца: Никита (Кемеровская обл.) и Idumeja (Чехия). 
Литература

1. Селекция озимого ячменя в Центральной России / В.С. Сидоренко, Е.Г. Филиппов, С.Н. Шевченко [и др.] // Зернобобовые и крупяные культуры. - 2014. - № 3 (11). C. $77-84$

2. Заушинцена А.В. История развития и результаты селекции ячменя в Кузнецкой котловине Западной Сибири // Аграрная наука Евро-Северо-Востока. - 2002 - № 3. С. 48-53.

3. Дятловская E. Агроинвестор, 26 июля 2019 г. - URL: [www.Agroinvestor.ru (дата обращения: 22.11.2019).

4. Лоскутов И.Г. Генетические ресурсы овса и ячменя - источник результативной селекции в России // Генетические ресурсы культурных растений в XXI веке: состояние, проблемы, перспективы: докл. ІІ Вавиловской междунар. конф. (Санкт-Петербург, 26-30 ноября 2007 г.). - СПб.: ВИР, 2009.

5. Методические указания по изучению и сохранению мировой коллекции ячменя и овса / под ред. И.Г. Лоскутова. - СПб., 2012. - 63 с.

6. ГОСТ 10840-64. Зерно. Методы определения натуры зерна. - М., 1964.

7. Методика полевого опыта. - М.: Колос, 1979. - 416 c.

8. Логинов Ю.П., Казак А.А., Якубышина Л.И. Сортовые ресурсы ячменя в Западной Сибири // Аграрный вестник Урала. - 2012. № 7 (99). - C. 8-10.

9. Сурин Н.A., Зобова Н.В., Ляхова Н.Е. Генетический потенциал и селекционная значимость ячменя Сибири // Вавиловский журнал генетики и селекции. - 2014. - Т. 18. № 2. - С. 378-386.

\section{Literatura}

1. Selekcija ozimogo jachmenja $v$ Central'noj Rossii / V.S. Sidorenko, E.G. Filippov, S.N. Shevchenko [i dr.] // Zernobobovye i krupjanye kultury. - 2014. - № 3 (11). S. 77-84.

2. Zaushincena A.V. Istorija razvitija i re-zul'taty selekcii jachmenja $v$ Kuzneckoj kotlovine Zapadnoj Sibiri // Agrarnaja nauka EvroSevero-Vostoka. - 2002 - № 3. - S. 48-53.

3. Djatlovskaja E. Agroinvestor, 26 ijulja 2019 g. - URL: [www. Agroinvestor.ru (data obra-shhenija: 22.11.2019).

4. Loskutov I.G. Geneticheskie resursy ovsa i jachmenja - istochnik rezul'tativnoj selekcii v Rossii // Geneticheskie resursy kul'turnyh rastenij $\vee$ XXI veke: sostojanie, problemy, perspektivy: dokl. II Vavilov-skoj mezhdunar. konf. (Sankt-Peterburg, 26-30 nojabrja 2007 g.). - SPb.: VIR, 2009.

5. Metodicheskie ukazanija po izucheniju i sohraneniju mirovoj kollekcii jachmenja i ovsa I pod red. I.G. Loskutova. - SPb., 2012. - 63 s.

6. GOST 10840-64. Zerno. Metody opredelenija natury zerna. - M., 1964.

7. Metodika polevogo opyta. - M.: Kolos, 1979. $416 \mathrm{~s}$.

8. Loginov Ju.P., Kazak A.A., Jakubyshina L.I. Sortovye resursy jachmenja v Zapadnoj Sibiri // Agrarnyj vestnik Urala. - 2012. - № 7 (99). S. 8-10.

9. Surin N.A., Zobova N.V., Ljahova N.E. Geneticheskij potencial i selekcionnaja znachi-most' jachmenja Sibiri // Vavilovskij zhur-nal genetiki i selekcii. - 2014. - T. 18. - № 2. - S. 378386 